\title{
Professional Development for High School Guidance Counselors to Facilitate Pre-college STEM Preparation (RTP)
}

\section{Richard A. Gearns, Stony Brook University}

Richard A. Gearns is a high school physics teacher and Ph.D. candidate in the Institute for STEM Education at Stony Brook University. He attended Buffalo State College where he received his B.S. and M.S. degrees in physics education. He was appointed a New York State Master Teacher in 2014. His research interest is in identifying and reducing barriers to STEM education opportunities for all students.

\section{Dr. Angela M. Kelly, Stony Brook University}

Angela M. Kelly is an Associate Professor of Physics and the Associate Director of the Science Education Program at Stony Brook University, New York. She attended La Salle University, Philadelphia, Pennsylvania, where she received her B.A. degree in chemistry, and completed her M.A. and Ph.D. degrees in science education (2000 and 2006, respectively) and her Ed.M. degree in curriculum and teaching (2007) at Teachers College, Columbia University, New York. She is the recipient of the SUNY Chancellor's Award for Excellence in Teaching (2016); the Provost's Faculty Recognition Award for Excellence in Scholarship and Research from Lehman College, City University of New York (2010); and the Outstanding Teaching Award from Teachers College, Columbia University (2006). Her research has been rooted in a commitment to equity in precollege and university science and engineering.

\section{Dr. Monica Bugallo, Stony Brook University}

Monica Bugallo is a Professor of Electrical and Computer Engineering and Faculty Director of the Women In Science and Engineering (WISE) Honors program at Stony Brook University. She received her B.S., M.S, and $\mathrm{Ph}$. D. degrees in computer science and engineering from University of A Coruna, Spain. She joined the Department of Electrical and Computer Engineering at Stony Brook University in 2002 where she is currently a Professor. Her research interests are in the field of statistical signal processing, with emphasis on the theory of Monte Carlo methods and its application to different disciplines including biomedicine, sensor networks, and finance. In addition, she has focused on STEM education and has initiated several successful programs with the purpose of engaging students at all academic stages in the excitement of engineering and research, with particular focus on underrepresented groups. She has authored and coauthored two book chapters and more than 150 journal papers and refereed conference articles.

Bugallo is a senior member of the IEEE, serves on several of its technical committees and is the current chair of the IEEE Signal Processing Society Education Committee. She has been part of the technical committee and has organized various professional conferences and workshops. She has received several prestigious research and education awards including the award for Best Paper in the IEEE Signal Processing Magazine 2007 as coauthor of a paper entitled "Particle Filtering," the IEEE Outstanding Young Engineer Award (2009), for development and application of computational methods for sequential signal processing, the IEEE Athanasios Papoulis Award (2011), for innovative educational outreach that has inspired high school students and college level women to study engineering, the Stony Brook University Hispanic Heritage Month (HHM) Latino Faculty Recognition Award (2009), and the Chair of Excellence by the Universidad Carlos III de Madrid-Banco de Santander (Spain) (2012). 


\title{
Professional Development for High School Guidance Counselors to Facilitate Precollege STEM Preparation (RTP)
}

\begin{abstract}
Research has shown that successful post-secondary study in engineering often depends upon precollege coursetaking in advanced mathematics and physics. Many high school students rely upon the guidance of their school counselors to select appropriate coursework to prepare them for their intended careers. School counselors are uniquely positioned to provide a realistic alignment of aspirations and prerequisite courses needed to succeed in a particular field. However, school counseling for science, technology, engineering, and mathematics (STEM) career pathways has often been limited, particularly for students in high needs schools. This study reports the results of a university-based professional development intervention for school counselors, where participants engaged in training in academic preparation for engineering study, outreach opportunities, bridge programs, as well as the variety of engineering disciplines accessible to students. University faculty in engineering and science education designed and implemented the workshop. Preliminary data from select counselor participants $(N=11)$ indicated that few had teaching experience before becoming a counselor, they advised an average of 251 students/year, they had little knowledge of the Next Generation Science Standards, and they could not differentiate among engineering disciplines. Most spent the majority of their professional time performing college counseling. They reported that women and minorities experience barriers to participation because of lack of knowledge of engineering pathways. Participants in the workshop improved their knowledge of engineering bridge programs and admissions, knowledge of the importance of specific high school coursework to improve success in post-secondary engineering, and knowledge of the importance of outreach participation to promote student interest in engineering. Qualitative data were analyzed to provide insights on improving the accessibility of post-secondary engineering for high school students, particularly those in high needs schools. Findings to date indicate professional development for school counselors is a promising intervention for recruiting and preparing students for engineering careers, an essential goal for maintaining technological innovation and economic vitality in the region and beyond.
\end{abstract}

\section{Introduction}

Recent reports have documented the persistent shortage of engineers in the U.S. [1], [2]. While high unemployment is not currently a major challenge across the country, the engineering sector continues to experience an ongoing inability to produce a sufficient quantity of skilled engineers, leading companies to seek talent offshore [3], partly due to a lack of engineering education in K12 schools [4], [5]. In addition, the graduation rate of engineering majors in higher education is $60 \%$ over six years [6]. Women and students of color have even higher attrition [7]. In 2014, there were 1,554,800 engineers in the U.S., of whom 1,382,500 were men, fewer than 60,000 were African American, and fewer than 80,000 were Hispanic [8]. American Indian and Alaska Natives comprise just $0.4 \%$ of the U.S. engineering workforce, totaling fewer than 10,000 individuals [9] among a population of 2.9 million nationally [10]. Students in pre-college settings need to be better prepared to study engineering and it is essential that greater efforts are made to strengthen pathways for diverse populations to enter the field [11], [12]. Plugging the leaks in the pipeline, while important, fails to address there are many non-linear pathways to STEM careers. 
Engineering students are attracted to the field from an array of entry points and careers diverge contingent upon subspecialties and education [13].

Role of school counseling in STEM preparation. Guidance counselors are often directly engaged in the career development process. Pre-college science and mathematics coursetaking has been shown to increase choice of STEM major and success in introductory college STEM courses [14], [15], suggesting the need for effective guidance early in the high school years [16]. However, the strength of counselor influence on career choice is low and this may be attributed to limited resources for performing a challenging job [17]. Student caseload has been cited as a key indicator of student success in transitioning from high school to college, with counselors advising less than 250 students more likely to speak to students about planning for college and taking college entrance requirements [18]. Effective training of school counselors is necessary to educate students about STEM majors and occupational choices [16]. Research has shown that this is particularly important for counselors serving low income populations, since these counselors often exhibit low expectations which may affect students' science and mathematics coursetaking and achievement [19], [20]. Counselors must be better positioned to assist students in aligning their career aspirations with the coursework necessary to achieve them [21]. This is essential for STEM fields where precollege coursetaking and performance in science and mathematics often predicts success in engineering undergraduate study [15].

A complicating matter for high school counselors is that students may be grouped into ability tracks when they arrive in high school. Ability groupings are not strictly academic but have social and political implications, as well [22]. Research has noted that tracking develops in middle and high schools as some students take more advanced courses that other students; for example, eighth grade algebra enrollment is a significant predictor of advanced science and mathematics coursetaking in high school [14]. Early pipeline STEM experiences have implications for future science and mathematics achievement and STEM career choice [12], [23].

Pre-college initiatives in STEM education. In an effort to encourage participation in precollege STEM coursework and expose students to engineering and design, school districts have adopted a variety of standards and curricular offerings. The ASEE K-12 STEM Guidelines for All Americans provides engineering knowledge and performance objectives for improving engineering literacy among pre-college students [24]. The recent adoption of the Next Generation Science Standards in 19 states and the District of Columbia has resulted in an increased emphasis on engineering and design experiences in K-12 science curricula [25]. Some school districts have adopted packaged programs that provide engineering curricular materials and training for teachers. Project Lead the Way, for example, allows schools to offer engineering experiences through design courses in a variety of disciplines [26]. University-based K-12 outreach programs have also shown promise in promoting engineering knowledge, self-efficacy, and interest [27]-[30]. It must be understood that, by necessity, knowledge of these standards and programs must be communicated to school counselors to increase student awareness and accessibility. Schools advocating for these programs have indicated their commitment to student preparation for STEM careers and school personnel should understand the mechanisms by which these programs do so. 
Research questions. This pilot, ongoing research explores the following overarching questions: How are school counselors prepared to offer advisement for engineering career preparation? In what ways and to what extent do school counselors interact with students to impact pre-college preparation for post-secondary engineering study and careers? In an effort to establish baseline data to answer these research questions, a professional development for school counselors was offered at Stony Brook University to provide preliminary training in STEM preparation for postsecondary academic success. Data were collected from a group of participants to understanding current counseling practices and how university-based training might improve their knowledge base to impact student participation and preparation for STEM in higher education.

\section{Study Design and Context}

Research design. This pilot study employed a convergent parallel mixed methods approach [31] to analyze counselors' reactions and ongoing professional development needs with regard to preparing and informing students about science and engineering career pathways. Pilot qualitative and quantitative data were collected simultaneously to determine school counselor practices and constraints related to STEM advisement.

Conceptual framework. The theoretical basis for the professional development design is derived from two psychosocial theories that explain academic and career choices. The theory of planned behavior suggests that students make academic decisions based upon their self-efficacy and sense of controllability [32]. That is, career intentions may be driven by a student's sense of how capable she is of achieving certain goals. Confidence in STEM-related academic tasks may be influenced by how school counselors view student STEM potential and how their practices may encourage or dissuade students from pursuing such tasks. The expectancy-value theory of motivation suggests that self-perception of ability and the extent to which students value certain academic outcomes are highly influential in career choice, persistence, and performance [33]. Students must be aware of STEM pathways and the variety of career opportunities in order to be motivated to set appropriate goals and select behaviors to meet these objectives [34]. These theories were incorporated in the professional development design.

Professional development structure. The intent of the university-based event was to provide school counselors with important information related to the preparation of pre-college students for success in post-secondary engineering study. The six-hour professional development workshop consisted of lectures by expert speakers, roundtable discussions, and interactive panels. Seventy school counselors were welcomed by the Dean of the College of Engineering and Applied Sciences (CEAS), who discussed the mission of CEAS and the growth of engineering disciplines in the regional economy and beyond. The Director of the Institute for STEM Education discussed the status of pre-college science education in New York State, particularly as it relates to student preparation in the physical sciences. He also discussed state adoption of the Next Generation Science Standards [25] and how this would affect K-12 science instruction. The Dean of Admissions and the Associate Provost for Enrollment and Retention Management provided information on university initiatives to diversify enrollment and application procedures. School counselors also learned about New York State's recently adopted Excelsior Scholarship Program - this program provides \$5500 in tuition per year to state 
residents attending a SUNY college provided household income is $\$ 100,000$ or less [35]. This information was particularly useful for counselors working with high needs students.

Roundtable discussion groups allowed participants to rotate through three different informative sessions. First, university administrators provided information on bridging programs to higher education, targeted for traditionally underserved students to increase early success in science and engineering coursework. Second, science education and physics faculty discussed pre-college preparation for STEM undergraduate majors, and how to inform students of the diversity of careers in engineering fields. Third, engineering and biology faculty discussed university outreach opportunities in engineering and science while leading counselors through tours of laboratories where high school students were performing engineering activities during daylong field trips to the university.

The last set of activities included two panel interactive discussions where school counselors could participate and ask questions. The first panel consisted of engineering faculty from biomedical engineering, computer science, electrical and computer engineering, and materials science. These faculty discussed student preparation, common student difficulties in introductory coursework, and engineering opportunities at CEAS. The second panel consisted of undergraduate and graduate engineering students, who discussed their academic experiences and challenges in CEAS.

Mixed methods research approach. This ongoing, pilot research study lays the foundation for a more comprehensive view of the role of guidance counselors in STEM career advising. The initial phase of the research included the results of a survey given to counselors at the end of the professional development workshop. Both quantitative and qualitative data were collected. Descriptive statistics were generated from the quantitative data. For the qualitative data, an iterative analysis process provided for the emergence and consolidation of common themes in counselor responses in engineering career advisement, particularly as related to underrepresented groups, with an eye toward analyzing how student-counselor interactions fit within the research team's conceptual framework - specifically, the synthesis of the theory of planned behavior with the expectancy-value model. The research team sought to uncover robust mechanisms that impeded or encouraged individual engineering career paths, wider STEM initiatives, and larger education opportunities, beginning in secondary schools and continuing to higher education [36].

Survey data were collected by recording the individual responses using an online survey platform, Qualtrics. The research team categorized qualitative survey data usingprovisional coding with elements of grounded theory by evaluating and classifying data based on its own characteristics and linking it to a conceptual framework [37]. The classification criteria were determined as the study unfolded. Different fragments of qualitative survey data were grouped by codes or phrases that captured the meaning [38]. Once data were coded, they were placed into various categories and it was possible to draw theoretically relevant conclusions [37].

Participants. Eleven counselors volunteered to complete the survey. These volunteers selfselected from a pool of 70 counselors who participated in the workshop. Survey data were collected from the school counselors towards the end of the professional development workshop to assess perceptions of the workshop and counselors' needs for future university-based training 
initiatives. The survey data from eleven volunteers including ten guidance counselors and one administrator representing eight suburban K-12 Long Island school districts ranging in enrollment from 2,752 to 6,480 students with per pupil spending ranging from $\$ 22,971$ to $\$ 30,676$. Five of the 11 counselors worked in high needs school districts.

Validity and reliability. Several strategies were employed for validating the initial findings. Triangulation of data through multiple data sources, namely surveys and open-ended questions as well as use of multiple researchers to acquire and analyze the data from the research subjects, served to bolster validity. Because of the strong desire to scale the professional development program, the researchers will work to increase the pool of research subjects to make comparisons in both similar and dissimilar program settings. Longitudinal data collection using follow-up interviews and surveys with research subjects will help determine if the ideas held by the research subjects persist over time.

\section{Results}

Data analysis revealed several interesting trends in school counselors' knowledge base and advisement practices. The results are summarized in terms of counselor workload, STEM advisement practices, desired professional development topics, and perceptions of the needs of traditionally underrepresented students in STEM.

Counselor workload. Counselors reported student caseloads ranging from a minimum of 200 students to maximum 300 students with a mean/median of 254/250 among the group. Counselor experience ranged from a low of two years to a high of 20 years with a mean/median of 11.5/14 years. The respondents had little teaching experience with only three of the eleven reporting classroom experience. These counselors had three, four, or six years in the classroom before going into guidance counseling. When asked whether students in their schools were matched or groomed for a career or major, respondents overwhelmingly (10 of 11) noted that students were neither matched nor groomed for a career or major. One respondent stated that students were matched to a career. No one indicated that students were groomed for a career.

Counseling students who need to build STEM credentials and performance. Respondents were asked how they might counsel students who want to be engineers but do not seem to have the skills and potential to be successful. The research team elicited three main thematic codes for counselor responses:

1. Building skills/competency/confidence in high school. These responses were generally interpreted to mean that counselors were willing to work with students within the school structure to help students build their STEM qualifications, improve their competence, and increase their confidence. They encouraged students to take high school courses that would help bolster their potential and post-graduation STEM-related options. Six of the 11 responses had elements of this category. A counselor might "advise them to take high level math and science courses," or "work with them on building those [STEM] skills." Three counselors indicated their districts offered Project Lead the Way programs, which was a resource for students interested in learning more about engineering and design. 
2. Seeking post-secondary remediation at a junior or community college. Many of the counselors suggested a post-high school solution. These responses indicated that students could improve their skills after high school and then have a greater potential for success in STEM at a four-year school. In this hypothetical scenario, counselors put themselves in the frame of advising a student who was close to the college application process rather than in the frame of helping a student in the beginning of her high school career. This finding corroborated other data that indicated career advising does not come to the fore until the students begin speaking with their counselor about colleges and universities in the $11^{\text {th }}$ or $12^{\text {th }}$ grade. For example, three counselors recommended future remediation at a community college. One counselor stated he would help students choose schools that would help them "...work their way up to having the potential to be successful in an engineering program at a later date."

3. Encouraging the student to go into a different field or finding a major more compatible with the student strength and abilities. Rather than finding ways to facilitate STEM career preparation, these responses indicated that counselors would help students find more compatible career choices based upon their skills and potential. Four counselors indicated they directly encouraged students to pursue options other than engineering with statements such as, "help them explore other career options," or "provide them with college major recommendations that are in line with their strengths/skill sets." Three responses indirectly recommended that students seek other career options by asking to students compare their skills to admission requirements with students left to draw their own conclusions about their readiness for an engineering program. The comparison was typically done at the end of the student's high school career when there were enough data points make relevant comparisons. Some counselors stated they encouraged students to explore engineering career options through an internship or job shadowing, encouraging students to "see for themselves" whether STEM careers were desirable and whether they wished to pursue them further.

Desire for professional development. In the opinion of the counselors, the most impactful part of the conference day was the keynote address. The presentation provided a general overview of STEM education in New York State and identified some of the gateway courses in STEM, particularly, identifying the "missing" engineering and technology course requirements in the graduation requirements. The presentation also highlighted the precipitous drop-off of physics course takers in NYS high schools, noting that $78 \%$ of STEM majors have taken physics in high school yet only $39 \%$ of U.S. high school students have taken physics [39], with much lower numbers in high needs schools [40]. This information was useful for counselors, many of whom were not aware of the importance of pre-college physics coursetaking for STEM achievement in higher education.

Counselors expressed a desire for additional professional development related to STEM education. Four counselors indicated they needed more information about engineering disciplines. In particular, they desired education on the variety of engineering disciplines and how they are differentiated from one another. Five of the respondents asked for more information on how a career might develop for a student if they should follow a particular STEM path. One respondent thought this might be best accomplished with a forum of STEM professionals that could talk about careers in STEM disciplines. Another respondent wanted to 
learn more about incorporating lessons in science classes showing how particular STEM pathways lead to various careers. Interestingly, no respondents expressed interest in how schools might provide better STEM education, which may be consequential since many guidance offices drive course offerings and scheduling. These responses suggest future interventions since counselors cannot provide early guidance for students if they do not understand the logistics of appropriate STEM career pathways.

Issues facing traditionally underrepresented students. When asked about the most significant issues facing underrepresented students who wish to pursue engineering (ethnic minorities and women), the counselors identified a variety of challenges. These fell into four categories: 1) personal financial issues, 2) lack of information about STEM opportunities and career requirements, 3) fields dominated by men, and 4) various cultural differences. Four of the respondents indicated that lack of information about STEM opportunities is a significant problem for underrepresented groups. Deficiencies in STEM career requirements were also cited frequently by counselors. Cultural differences were also cited, including social stigma, lack of interest and personal financial issues.

Study limitations. There are several limitations to the research. The sample size was small, yet future research will involve more comprehensive data collection from additional subjects. Also, counselors are not the only influence on student career choice. The process of choosing a career involves an extremely complex set of conscious and unconscious information gathering, evaluation, and decisions that occur over years [41], with the process starting as early as middle school [42]. Parents too have a significant influence in the STEM self-efficacy of their children and their subsequent career choices [43]. However, some students have expressed dismay that they were underserved by school staff and they would be better positioned for post-secondary success by more comprehensive high school preparation in STEM coursework and career counseling. Therefore, academically motivated students may instead seek career advice from family, peers, and teachers [44], consequently diminishing the effectiveness of counselor professional development.

\section{Discussion}

Preliminary data from the counselors confirmed existing research in the field and revealed some areas that could benefit from additional exploration. The research team found the counselor caseload averaged 251 students. While this average is in line with the American School Counselor Association recommendation of 1:250 [45], it is important to note that this recommendation is not based on research. However, students in schools with high counselor caseloads are less likely to speak to their counselors, less likely to initiate plans to attend college, and therefore less likely to attend a four-year school [18]. Four schools in the study exceeded the recommended ratio with numbers of 270, 280, 285, and 300. Consequently, if students are less likely to talk to a "busy" counselor, then their choices of college prerequisites may also be affected. Student post-secondary success in engineering hinges upon rigorous course taking in high school [15], [46]. These findings suggest that counselors will recommend rigorous, upper level science and mathematics courses for students that express an interest in engineering as a career. However, because counselors by and large neither groom nor match students for a career, their advice often comes too late in the 11 th or $12^{\text {th }}$ grade when students are preparing to engage 
the college entrance process. For underrepresented groups, inadvertent tracking may occur because of separation from their classmates for ability groupings, remedial work, or English language learning. This exacerbates the problem. It is often difficult for some of these students to find their way to the highest-level courses because they do not meet the prerequisites due to decisions made by school staff early in the student's education [47]. Our preliminary data revealed that many counselors were advising students in a reactive mode by offering remediation, alternative career choices, or community colleges for students who aspired to engineering careers but were not perceived as qualified for admission.

Counselor advice in many instances was indirect. As a result, many students may not have received strong advice to pursue a particular career direction of interest. The literature has shown that in some contexts, counselors have not given science learning high priority, and they discouraged students from taking science because it is "hard" or "not for everyone," portraying science as a subject some people can do and others cannot [20], [48]. As result, students advised in this way often do not find out they need mathematics or science college prerequisites until late in the college application process. Counselors in many instances are not aware that there are many faces and abilities in STEM students.

Counselors were aware of significant issues facing underrepresented groups. Responses ranged from personal financial issues, lack of information about STEM opportunities and career requirements, social stigma, and other cultural differences. Lack of information about STEM opportunities and career requirements might be linked to less frequent college meetings of underrepresented groups with counselors. This may be, in part, due to inadvertent tracking as these students might be on a different course taking path that does not "trigger" the counselor to discuss STEM possibilities with them. It is known that counselors provide students with social capital or relationships that lead to taking action [49]. There is also some indication that students of counselors with smaller caseloads gain more social capital because counselors may meet with these students more often and therefore expose them to college information more frequently [18]. As a result, because underrepresented ethnic minorities often cannot take higher-level coursework, they are not being invited to discuss STEM or other career options with their counselors as early as other students. We would like to expand this area of research.

Because many counselors themselves are unclear about the opportunities in STEM fields as well as the various disciplines and their career paths, the lack of information counselors have at their disposal may result in lack of recognition of promising STEM candidates. The data revealed that counselors need additional information about STEM careers. Counselors typically do not have a personal background in STEM, therefore, many are in need of substantial career background, information particularly in specialized science and engineering fields. Many also asked for information on what students can expect in engineering careers. This also informs future research in that counselors cannot provide early guidance for students if they themselves cannot articulate STEM career pathways.

Future research. The data from this research will be utilized to design effective interventions for school counselors to address their professional needs. These will include information about STEM disciplines, early engineering opportunities for students, and STEM career expectations. Longitudinal data collection will be employed to follow the counselors and assess changes in 
their guidance practices. Using university admissions and enrollment data, the research team hopes to correlate positive changes in student enrollment and STEM career choice with improved counselor practices initiated by the professional development intervention. These outcomes will be compared with schools whose counselors did not participate in the intervention. Counseling practices in both low and high needs schools will be measured and compared. As a work in progress, the research team is looking to address some weaknesses in the survey. Some questions will be broadened while others will be more focused. Additional questions suitable for factor analysis will be added. Follow-up interviews using a semi-structured approach will be used to clarify and expand counselor responses. Student focus-group interviews will be employed to study counselor practices from their perspectives.

Conclusions. It is essential that educators look for new and innovative ways to encourage the growth of STEM participation. Students who enter the STEM pipeline at the earliest ages stand the best chance of continuing on career paths that will bring them greater economic prosperity. By increasing the opportunities for a greater and more diverse population of students to have accessibility to these subjects, the greater the number of curious, scientifically literate students will be prepared to learn and pursue engineering careers.

\section{Acknowledgments}

This material is based upon work supported by the National Science Foundation (under Grant No. 1647405) and National Grid. Any opinions, findings, and conclusions or recommendations expressed in this material are those of the authors and do not necessarily reflect the views of the funding partners. 


\section{References}

[1] J. P. Holdren, M. Cora, and S. Suresh. Federal STEM Education, 5 Year Strategic Plan: A Report from the Committee on STEM Education. Washington, DC: National Science Technology Council, Office of the President of the United States, 2013.

[2] National Research Council. Changing the Conversation: Messages for Improving Understanding of Engineering. Washington, DC: National Research Council, 2008.

[3] A. Lewin, S. Massini, and C. Peeters, "Why are companies offshoring innovation? The emerging global race for talent." Journal of International Business Studies, vol. 40, pp. 901-925, 2009.

[4] L. Katehi, G. Pearson, and M. Feder, M. Engineering in K-12 Education. Washington, DC: Committee on K-12 Engineering Education, National Academy of Engineering and National Research Council of the National Academies, 2009.

[5] National Academy of Engineering, "K-12 education," The Bridge, vol. 39, 2009.

[6] National Science Board. Moving Forward to Improve Engineering Education (NSB Publication No. 07-122). Arlington, VA: National Science Foundation, 2007.

[7] S. G. Brainard and L. Carlin, "A six-year longitudinal study of undergraduate women in engineering and science," Journal of Engineering Education, vol. 87, pp. 369-375, 1998.

[8] National Science Foundation. Women, Minorities, and Persons with Disabilities in Science and Engineering. Arlington, VA: National Science Foundation, 2017.

[9] National Action Council on Minorities in Engineering. Research and Policy: American Indians in Engineering. White Plains, NY: NACME, Inc., 2012. [Online]. Available: http://www.nacme.org/publications/research briefs/NACMEAmerican_Indian.pdf [Accessed April 20, 2018].

[10] U.S. Census Bureau. The American Indian and Alaska Native Population: 2010. Washington D.C.: U.S. Department of Commerce, 2012. [Online] Available: https://www.census.gov/prod/cen2010/briefs/c2010br-10.pdf [Accessed 18 Apr. 2018].

[11] H. Kimmel, J. Carpinelli, and R. Rockland, "Bringing engineering into K-12 schools: A problem looking for solutions?" Proceedings of the 2006 ASEE Annual Conference, 2006.

[12] President's Council of Advisors on Science and Technology. Prepare and Inspire: K-12 Education in Science, Technology, Engineering, and Math (STEM) for America's Future. Washington, DC: Office of Science and Technology Policy, 2010.

[13] S. M. Malcom, M.A. Feder, Barriers and Opportunities for 2-year and 4-year STEM Degrees: Systemic Change to Support Diverse Student Pathways. Washington D.C.: National Academies Press, 2016.

[14] J. Trusty, "Effects of high school course-taking and other variables on choice of science and mathematics college majors," Journal of Counseling and Development, vol. 80, pp. 464474, 2002.

[15] W. Tyson, "Modeling engineering degree attainment using high school and college physics and calculus coursetaking and achievement," Journal of Engineering Education, vol. 100, pp. 760-777, 2011.

[16] M. E. Engberg and G. C. Wolniak, "College student pathways to the STEM disciplines," Teachers College Record, vol. 115, pp. 1-17, 2013. 
[17] S. A. Amoah, I. Kwofie, and F. A. Kwofie, "The school counsellor and students' career choice in high school: The sssessor's perspective in a Ghanaian case," Journal of Education and Practice, vol. 6, pp. 57-65, 2015.

[18] C. S. Woods and T. Domina, "The school counselor caseload and the high school-to-college pipeline, Teachers College Record, vol. 116, pp. 1-30, 2014.

[19] C. W. West-Olatunji, L. Shure, R. Pringle, T. Adams, D. Lewis and B. Cholewa, "Exploring how school counselors position low-income African American girls as mathematics and science learners," Professional School Counseling, vol.13, pp. 184-195, 2010.

[20] A. M. Kelly, "Physics teachers' perspectives on factors that affect urban physics participation and accessibility," Physical Review Physics Education Research, vol. 9, 010122, 2013. [Online]. Available: http://link.aps.org/doi/10.1103/PhysRevSTPER.9.010122. [Accessed March 4, 2018].

[21] D. T. Sciarra, "Predictive factors in math course-taking in high school," Professional School Counseling, vol. 13, pp. 196-207, 2010.

[22] S. Yonezawa and M. Jones, "Students' perspectives on tracking and detracking," Theory into Practice, vol. 45, pp. 15-23, 2006.

[23] M. Issapour and A. M. Kelly, "How student gender, SAT scores and interest in science relates to their performance in introductory coursework in engineering technology," Integrated STEM Education Conference (ISEC), 2015 IEEE $5^{\text {th }}$ (pp. 221-224), Princeton, NJ.

[24] American Society for Engineering Education. K-12 STEM Guidelines for All Americans. Washington, DC: ASEE Corporate Member Council, 2008.

[25] NGSS Lead States. The Next Generation Science Standards: For States, By States. Washington, DC: National Academies Press, 2013.

[26] Project Lead the Way, Inc. PLTW Engineering (9-12). Indianapolis, IN: Project Lead the Way, Inc., 2018. [Online]. Available: https://www.pltw.org/our-programs/pltwengineering. [Accessed March 1, 2018].

[27] M. F. Bugallo and A. M. Kelly, "Engineering outreach: Yesterday, today, and tomorrow," IEEE Signal Processing Magazine, vol. 34, pp. 69-100, 2017.

[28] M. F. Bugallo and A. M. Kelly, "An outreach afterschool program to introduce high school students to electrical engineering," International Conference on Acoustics, Speech, and Signal Processing (pp. 5540-5544), Brisbane, Australia, 2015.

[29] M. F. Bugallo and A. M. Kelly, "A pre-college recruitment strategy for electrical and computer engineering study," Integrated STEM Education Conference (ISEC) IEEE 2014 (pp. 1-4), Princeton, NJ, 2014.

[30] M. F. Bugallo, A. M. Kelly, and M. Ha, "Research on impacts of a university-based electrical and computer engineering summer program for high school students," International Journal of Engineering Education, vol. 31, pp. 1419-1427, 2015.

[31] J. W. Creswell and J. D. Creswell. Research Design: Qualitative, Quantitiative, and Mixed Methods Approaches (5th ed.). Los Angeles, CA: Sage, 2018.

[32] I. Ajzen, "Perceived behavioral control, self-efficacy, locus of control, and the theory of planned behavior," Journal of Applied Social Psychology, vol. 32, pp. 665-683, 2002.

[33] A. Wigfield and J. S. Eccles, "Expectancy-value theory of achievement motivation," Contemporary Educational Psychology, vol. 25, pp. 68-81, 2000.

[34] A. M. Kelly, "Social cognitive perspective of gender disparities in undergraduate physics," Physical Review Physics Education Research, vol. 12, 020116, 2016. [Online]. 
Available: https://doi.org/10.1103/PhysRevPhysEducRes.12.020116. [Accessed March 4, 2018].

[35] New York State Higher Education Services Corporation. Excelsior Scholarship. Albany, NY: Higher Education Services Corporation, 2018. [Online]. Available: https://www.hesc.ny.gov/excelsior/. [Accessed March 1, 2018].

[36] R. A. Streveler and K. A. Smith, "Conducting rigorous research in engineering education," Journal of Engineering Education, vol. 95, pp. 103-105, 2006.

[37] B. G. Glaser and A. L. Strauss. The Discovery of Grounded Theory: Strategies for Qualitative Research. Chicago: Aldine, 1967.

[38] J. Saldaña. The Coding Manual for Qualitative Researchers. Thousand Oaks, CA: Sage, 2013.

[39] American Institute of Physics. High School Physics Courses and Enrollments: Results from the 2012-13 Nationwide Survey of High School Physics Teachers. College Park, MD: AIP Statistical Research Center, 2014.

[40] A. M. Kelly and K. Sheppard, "The relationship between the urban small schools movement and access to physics education," Science Educator, vol. 19, pp. 14-25, 2010.

[41] W. Mihal, P. Sorce, and T. Comte, "A process model of individual career decision making," The Academy of Management Review, vol. 9, pp. 95-103, 1984.

[42] E. Tan, A. Calabrese Barton, H. Kang, and T. O'Neill, "Desiring a career in STEM-related fields: How middle school girls articulate and negotiate identities-in-practice in science," Journal of Research in Science Teaching, vol. 50, pp. 1143-1179, 2013.

[43] S. Turner and R. T. Lapan, "Career self-efficacy and perceptions of parent support in adolescent career development," The Career Development Quarterly, vol. 51, pp. 44-55, 2002.

[44] R. Gearns, A. M. Kelly, and M. F. Bugallo. Shifts in Students' Views Towards Engineering in an Out-of-School-Time Program. Poster presented at the Annual Conference of the National Association of Research in Science Teaching, San Antonio, TX.

[45] American School Counselor Association. The Role of the School Counselor. Alexandria, VA: ASCA, 2018. [Online]. Available: https://www.schoolcounselor.org/asca/media/asca/Careers-Roles/RoleStatement.pdf. [Accessed March 1, 2018].

[46] M. C. Long, D. Conger, and P. Iartarola, "Effects of high school course-taking on secondary and postsecondary success," American Educational Research Journal, vol. 49, pp. 285$322,2012$.

[47] T. Chambers, “The 'receivement gap': School tracking policies and the fallacy of the 'achievement Gap," The Journal of Negro Education, vol. 78, pp. 417-431, 2009.

[48] P. R. Aschbacher, E. Li, and E. J. Roth, "Is science me? High school students' identities, participation and aspirations in science, engineering, and medicine," Journal f Research in Science Teaching, vol. 47, pp. 564-582, 2010.

[49] J. S. Coleman, "Social capital in the creation of human capital," The American Journal of Sociology, vol. 94, pp. S95-S120, 1988. 